\title{
Bibliometric study to assist research topic selection: a case from research design on Jakarta's groundwater (part 1)
} \author{
Kaesar Fahmi\# \\ ‡ Faculty of Earth Sciences and Technology. Bandung Institute of Technology, Bandung, Indonesia \\ $\S$ Civil Engineering and Port Innovation, Delft University, Delft, Netherlands \\ | University of Sydney, Sydney, Australia \\ I Groundwater Engineering Program, Bandung Institute of Technology, Bandung, Indonesia \\ \# Universitas Pendidikan Indonesia, Bandung, Indonesia
}

Dasapta Erwin Irawan¥, Adhi Priyambodho§, Cut Novianti Rachmil, Dimas Maulana Wibowo", Andita

Corresponding author: Dasapta Erwin Irawan (dasaptaerwin@outlook.co.id)

Received: 12 Jul 2016 | Published: 19 Jul 2016

Citation: Irawan D, Priyambodho A, Rachmi C, Wibowo D, Fahmi A (2016) Bibliometric study to assist research topic selection: a case from research design on Jakarta's groundwater (part 1). Research Ideas and Outcomes 2: e9841. doi: 10.3897/rio.2.e9841

\section{Abstract}

This paper is an example to visualize bibliometric data to extract paper's topics and their citation relation. It is very important to evaluate the number of documents, the intensity of the paper's topic, and the relationship between papers. The output can be used to pinpoint suitable research topic.

We began with 246 papers, gathered from Google Scholar, Crossref, and Scopus database. We narrowed them down to 70 papers based on language, relevance, pdf availability, and metadata completeness. Open source tools, Vosviewer, ZoteroPaperMachine plugin, were used to visualize the existing reference database.

The following paper gives an illustration that a brief bibliometric analysis could assist a researcher to determine our research path. It gives us a glimpse of research landscape in Jakarta area. Therefore for deeper analysis, we will focus our literature review on groundwater and surface water interactions. 


\section{Keywords}

Bibliometric, literature review, groundwater, Jakarta

\section{Introduction}

Floods have been the main issue in Jakarta every year. Heavy flood occurred in 1996, 2002 and 2007, inundating up to $40 \%$ of the city (Brinkman and Hartman 2008). An annual report from BNPB in 2013 has shown worse flooding. Such hazard is not going to decrease without proper water management (Lubis et al. 2008, Delinom et al. 2009). Therefore, this paper tries to come up with a bibliometric analysis of literature on Jakarta's groundwater setting as a tool to design further research on the subject.

\section{Methods}

The following bibliometric method was based on several papers on bibliometric (Leeds_University_Library 2014, Thomson_Reuters 2008, Ziegler 2009, Fang and (supv) 2004, Schwartz and Fang 2007, Schwartz and Ibaraki 2001, Yuan-zheng et al. 2015, Niu et al. 2014, and Zahedi and Eck 2014). In a recent development, a group of scientists from Leiden University have developed Vosviewer application for bibliometric analysis and its visualization (van Eck and Waltman 2009, Van Eck and Waltman 2011, van Eck and Waltman 2013). We also use Zotero (Zotero_Community 2016) with PaperMachine plug-in (Guldi and Roberson 2011) to extracts word cloud and text referral. We used the keyword

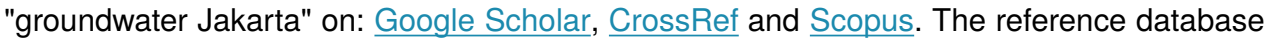
was saved as *.ris (Wikipedia 2016), then parsed into the applications. We began with 246 papers, then narrowed them to 70 papers based on language, relevance, pdf availability, and metadata completeness.

\section{Data resources}

Dataset is available on Figshare (Irawan et al. 2016).

\section{Results and discussion}

The first result is 47 clusters of paper sorted by keywords, produced by Vosviewer. Only five clusters are connected (Fig. 1). Connected clusters consists of the following topics: urban heat island, urban water quality, river water-groundwater interaction, groundwater pumping, and land subsidence. 


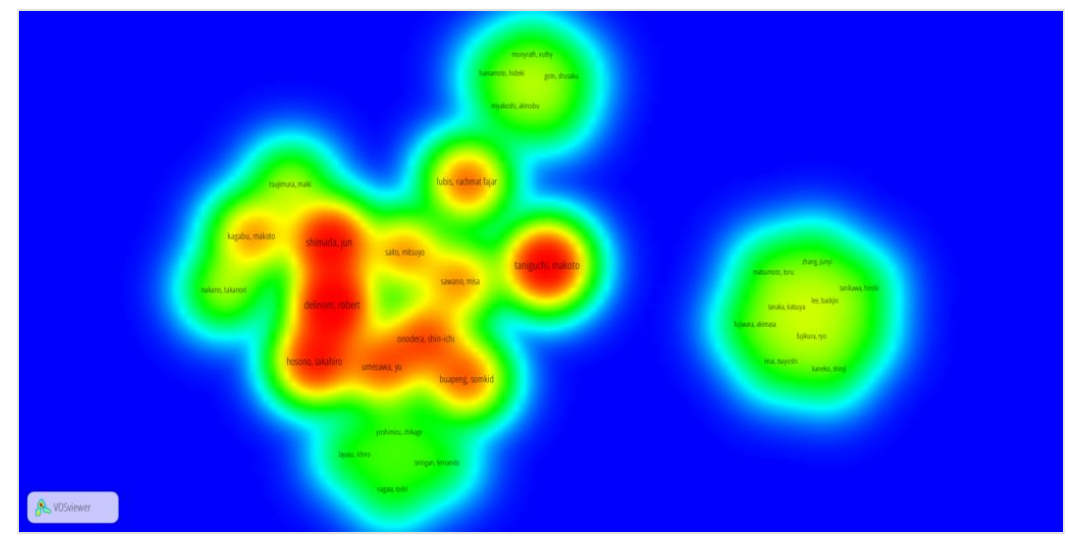

Figure 1.

Density map of the papers based on the key words (Red: dense paper population, green: less dense). Dataset is available as Suppl. material 1 (in Irawan et al. 2016).

Word cloud_analysis in the 1987-2003 show no significant words related to groundwater, while word cloud in 2004-2005 papers starts to show words like "population growth" and "land use". Then in 2005-2006, we could see more mapping-related terms (local/large scale) and quality terms (water contamination and domestic waste), also socio economic terms (richness and indicator). Papers in 2006-2007 mention words like urban development, environment and contamination which reflect the awareness to environmental sustainability. Then in 2007-2008 terms like ecosystem and infrastructure were used. In the following years, technical water-related words like floods, water quality, urbanization, land subsidence, interferometry, and aquifer/groundwater restoration were exposed. Figures are available in Suppl. material 2 (Irawan et al. 2016).

\section{Conclusions}

Visualization of bibliometric data could help researchers to pinpoint research path. In this case, the analysis presents a glimpse of groundwater research in Jakarta. We believe more researches should be directed to groundwater-surface water interactions.

\section{Acknowledgements}

We thank ITB for giving partial funding and Applied Geology Research Group for valuable comments. 


\section{Funding program}

This research is partially funded by 2016 Bandung Institute of Technology (BIT) Research Grant.

\section{Grant title}

Assessment of Jakarta's water resources.

\section{Hosting institution}

Bandung Institute of Technology, Indonesia

\section{Author contributions}

- DEl: idea, drafting

- AP: search keys

- $\quad$ CNR: drafting

- $\quad$ DMW and AKF: reference search

\section{Conflicts of interest}

The authors state no competing interest upon the publication of this work.

\section{References}

- $\quad$ Brinkman J, Hartman M (2008) Jakarta Flood Hazard Mapping Framework. http:// www.hkv.nl/upload/publication/Jakarta Flood Hazard Mapping Framework MH.pdf. Accession date: 2016504.

- Delinom R, Assegaf A, Abidin H, Taniguchi M, Suherman D, Lubis RF, Yulianto E (2009) The contribution of human activities to subsurface environment degradation in Greater Jakarta Area, Indonesia. Science of The Total Environment 407 (9): 3129-3141. DOI: 1 0.1016/j.scitotenv.2008.10.003

- $\quad$ Fang Y, (supv) FS (2004) Scientific research impact and data mining applications in hydrogeology. The Ohio State University, Ohio, 136 pp. [In English]. URL: http:// dl.acm.org/citation.cfm?id=1048351

- $\quad$ Guldi J, Roberson CJ (2011) PaperMachines: Zotero plug-in for text mining and visualisation. PaperMachines. URL: http://papermachines.org 
- Irawan DE, Priyambodho A, Rachmi CN, Wibowo DM, Fahmi AK (2016) Literature visualisation: Bibliometric of groundwater research in Jakarta. Figshare 1 (2): 1. [In English]. DOI: 10.6084/M9.FIGSHARE.3405685

- Leeds_University_Library (2014) Bibliometrics: an overview. https://library.leeds.ac.uk/ downloads/file/265/bibliometrics_an_overview. Accession date: 2016501.

- Lubis RF, Sakura Y, Delinom R (2008) Groundwater recharge and discharge processes in the Jakarta groundwater basin, Indonesia. Hydrogeology Journal 16 (5): 927-938. DOI: $10.1007 / \mathrm{s} 10040-008-0278-1$

- $\quad$ Niu B, Loáiciga H, Wang Z, Zhan FB, Hong S (2014) Twenty years of global groundwater research: A Science Citation Index Expanded-based bibliometric survey (1993-2012). Journal of Hydrology 519: 1. [In English]. DOI: 10.1016/ j.jhydrol.2014.07.064

- $\quad$ Schwartz F, Fang YC (2007) Citation data analysis on hydrogeology. Journal of the American Society for Information Science and Technology 58 (4): 1. [In English]. DOI: 1 $\underline{0.1002 / a s i .20526}$

- $\quad$ Schwartz F, Ibaraki M (2001) Hydrogeological Research: Beginning of the End or End of the Beginning? Ground Water 39 (4): 492-498. DOI: 10.1111/ j.1745-6584.2001.tb02337.x

- $\quad$ Thomson_Reuters (2008) WHITEPAPER USING BIBLIOMETRICS: A guide to evaluating research performance with citation data. http://ipscience.thomsonreuters.com/m/pdfs/325133 thomson.pdf. Accession date: 2016504.

- $\quad$ van Eck NJ, Waltman L (2009) Software survey: VOSviewer, a computer program for bibliometric mapping. Scientometrics 84 (2): 523-538. DOI: 10.1007/s11192-009-0146-3

- $\quad$ van Eck NJ, Waltman L (2013) VOSviewer manual. Leiden: Univeristeit Leiden 1: 1. URL: www.vosviewer.com/documentation/Manual VOSviewer 1.5.4.pdf

- Van Eck NJ, Waltman L (2011) Text mining and visualization using VOSviewer. arXiv preprint arXiv:1109.2058 1: 1. URL: http://arxiv.org/abs/1109.2058

- Wikipedia (2016) RIS (file format). https://en.wikipedia.org/wiki/RIS_(file_format). Accession date: 2016706.

- Yuan-zheng Z, Shi-jie J, Yan-guo T, Jin-sheng W, Hong-biao GU, Liang XIE, Zhi-hua YIN (2015) Thirty years (1984-2014) of groundwater science teaching and research in China: A dissertation-based bibliometric survey. Journal of Groundwater Science and Engineering 3 (3): 1. URL: http://gwse.iheg.org.cn/EN/abstract/abstract190.shtml

- Zahedi Z, Eck NJv (2014) Visualizing readership activity of Mendeley users using Vosviewer. Figshare 1: 1. [In English]. DOI: 10.6084/M9.FIGSHARE.1092521.V1

- Ziegler B (2009) Methods for Bibliometric Analysis of Research: Renewable Energy Case Study. http://web.mit.edu/smadnick/www/wp/2009-10.pdf. Accession date: 20165 04.

- Zotero_Community (2016) Zotero: An open source reference manager. Zotero Community. URL: http://zotero.org 


\section{Supplementary materials}

\section{Suppl. material 1: List of original papers}

Authors: Irawan, D,E.

Data type: text

Brief description: This file stored the list of 70 papers discussed in the article.

Filename: GwJakarta.csv - Download file (5.59 kb)

\section{Suppl. material 2: Word cloud 1987-2015}

Authors: Irawan, D.E.

Data type: images

Brief description: This pdf consists of word cloud (1987-2015) images discussed in the paper Filename: wordcloud_longitudinal.pdf - Download file (320.96 kb) 